Article

\title{
Evolution of Surface Nanopores in Pressurised Gyrospun Polymeric Microfibers
}

\author{
U. Eranka Illangakoon *, Suntharavathanan Mahalingam, Rupy K. Matharu \\ and Mohan Edirisinghe \\ Department of Mechanical Engineering, University College London, London WC1E 7JE, UK; \\ suntharavathanan.mahalingam@ucl.ac.uk (S.M.); rupy.matharu.15@ucl.ac.uk (R.K.M.); \\ m.edirisinghe@ucl.ac.uk (M.E.) \\ * Correspondence: ucnvuei@ucl.ac.uk
}

Received: 19 September 2017; Accepted: 6 October 2017; Published: 13 October 2017

\begin{abstract}
The selection of a solvent or solvent system and the ensuing polymer-solvent interactions are crucial factors affecting the preparation of fibers with multiple morphologies. A range of poly(methylmethacrylate) fibers were prepared by pressurised gyration using acetone, chloroform, $\mathrm{N}, \mathrm{N}$-dimethylformamide (DMF), ethyl acetate and dichloromethane as solvents. It was found that microscale fibers with surface nanopores were formed when using chloroform, ethyl acetate and dichloromethane and poreless fibers were formed when using acetone and DMF as the solvent. These observations are explained on the basis of the physical properties of the solvents and mechanisms of pore formation. The formation of porous fibers is caused by many solvent properties such as volatility, solubility parameters, vapour pressure and surface tension. Cross-sectional images show that the nanopores are only on the surface of the fibers and they were not inter-connected. Further, the results show that fibers with desired nanopores $(40-400 \mathrm{~nm})$ can be prepared by carefully selecting the solvent and applied pressure in the gyration process.
\end{abstract}

Keywords: pressure; gyration; polymer; microfibers; nanopores; surface

\section{Introduction}

Ultra-thin fibers have been generated by using various fabricating techniques such as self-assembly, phase separation, drawing, template synthesis, electrospinning [1-4] and pressurised gyration [5-8]. Among these state-of-the-art techniques, more recently discovered pressurised gyration has attracted much attention due to higher production rate and low cost. Since 2013, this technique is widely used to prepare nano- to micro-scale fibers for various applications such as drug delivery [9] and biopharmaceutical applications $[8,10]$. The pressurised gyration method utilises both centrifugal spinning and solution blowing simultaneously [5].

The basic gyration set-up consists of a rotary aluminum vessel, which contains a series of pin-hole type orifices along its circumference, a high-pressure gas supply, a DC motor and a speed controller. The top of the rotary vessel is connected to a high-pressure gas supply that is capable of producing pressures up to $3 \times 10^{5} \mathrm{~Pa}$, and the bottom is connected to a DC motor-which is used to rotate the vessel. The polymer solution is placed in the gyration vessel. The centrifugal force created due to high-speed rotation together with the high-pressure gas supply consequently results in fibers extruding through the orifices of the gyration vessel. The polymer jet travels through air during which the solvent evaporates and solid fibers are deposited on the collector. Previous work on pressurised gyration shows that fiber diameter and morphology can be changed by varying the polymer concentration, rotational speed of the vessel and the working pressure $[5,7,11]$. Recent studies of polymer-protein solutions have also shown that pressurised gyration is capable of generating microbubbles rather than fibers by controlling the rotational speed and applied pressure within a certain range [9]. 
Polymer-solvent interactions determine the properties of the spinning solution [12]. When a polymer is highly soluble in a solvent, it will form strong polymer-solvent interactions where the polymer chains swell and expand to maximise the intermolecular interactions and when a polymer is less soluble the polymer chains contract and stay closer to each other to minimise the polymer-solvent interactions [6,13]. It is well known that the spinning solution parameters strongly depend on the polymer and solvent used to dissolve the polymer. Therefore, the properties of the solvent such as boiling point, surface tension, vapour pressure and the solution parameters show a profound effect on fiber morphology. The effect of solvents on electrospun nanofibers were reported by various researchers using different polymers such as poly(methylmethacrylate) (PMMA) [14-16],

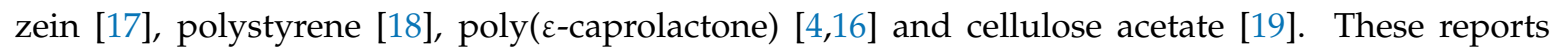
have showed that fibers with hierarchical structures can be obtained when using solvents with higher vapour pressure [20]. It is a well-known phenomenon that a volatile solvent plays a pivotal role in the generation of fibers with different surface morphologies such as porous, wrinkled and smooth $[1,14,21]$. Even though the formation of these hierarchical structures is not fully understood, phase separation and breath figure approach can be used to explain the formation of these structures. Fibers with hierarchical secondary structures have advantages compared to fibers with smooth surfaces such as higher surface-area-to-volume ratio, super-hydrophobicity or super-hydrophilicity, high rate of adsorption, low density and high surface volume and fibers with these characteristics can be used in various areas such as drug delivery, tissue engineering and electronics [22-24].

PMMA is an amorphous, transparent thermoplastic polymer widely used in biomedical applications such as bone implants [25,26], prosthetics [27], dentistry [28-30], drug delivery [31], cosmetic surgeries and as intraocular lenses [32] implanted after cataract surgery. PMMA was selected as the model polymer for this study due to its high solubility in a wide range of solvents. Hierarchical structures of PMMA were prepared by several researchers [33,34] using electrospinning as the fiber-making technique. However, such a study has not been performed using pressurised gyration and, in this work, we are reporting the formation of hierarchical structures of PMMA using this forming route.

\section{Experimental Details}

\subsection{Materials}

Poly(methylmethacrylate) of molecular weight 120,000 g/mol, chloroform, acetone, $\mathrm{N}, \mathrm{N}$-dimethylformamide (DMF), ethyl acetate and dichloromethane (DCM) were obtained from Sigma-Aldrich (Gillingham, UK). All reagents were analytical grade and were used as received.

\subsection{Preparation of Spinning Solutions}

A series of $20 \mathrm{wt} \%$ PMMA solutions were prepared by dissolving PMMA in chloroform, acetone, $\mathrm{N}, \mathrm{N}$-dimethylformamide (DMF), ethyl acetate and dichloromethane (DCM). All the polymer solutions were magnetically stirred for $24 \mathrm{~h}$ to obtain homogeneous solutions.

\subsection{Pressurised Gyration}

Figure 1 shows the experimental set-up of the pressurised gyration process. The rotary aluminum cylindrical vessel ( $\sim 60 \mathrm{~mm}$ in diameter and $\sim 35 \mathrm{~mm}$ in height) contains 24 orifices on its face, each having a diameter of $0.5 \mathrm{~mm} ; 6 \mathrm{~mL}$ of the polymer solution was placed in the vessel and spun at 36,000 rpm using 0.1 MPa working pressure. Polymer solutions made using chloroform, DCM and ethyl acetate were spun at 0, 0.2, 0.3 MPa to obtain fiber samples under different working pressures. PMMA fibers were collected using a rod-collector placed $100 \mathrm{~mm}$ away from the vessel. All the spinning experiments were carried out under ambient conditions $\left(25 \pm 2{ }^{\circ} \mathrm{C}\right.$ and relative humidity $47 \% \pm 3 \%$ ). 


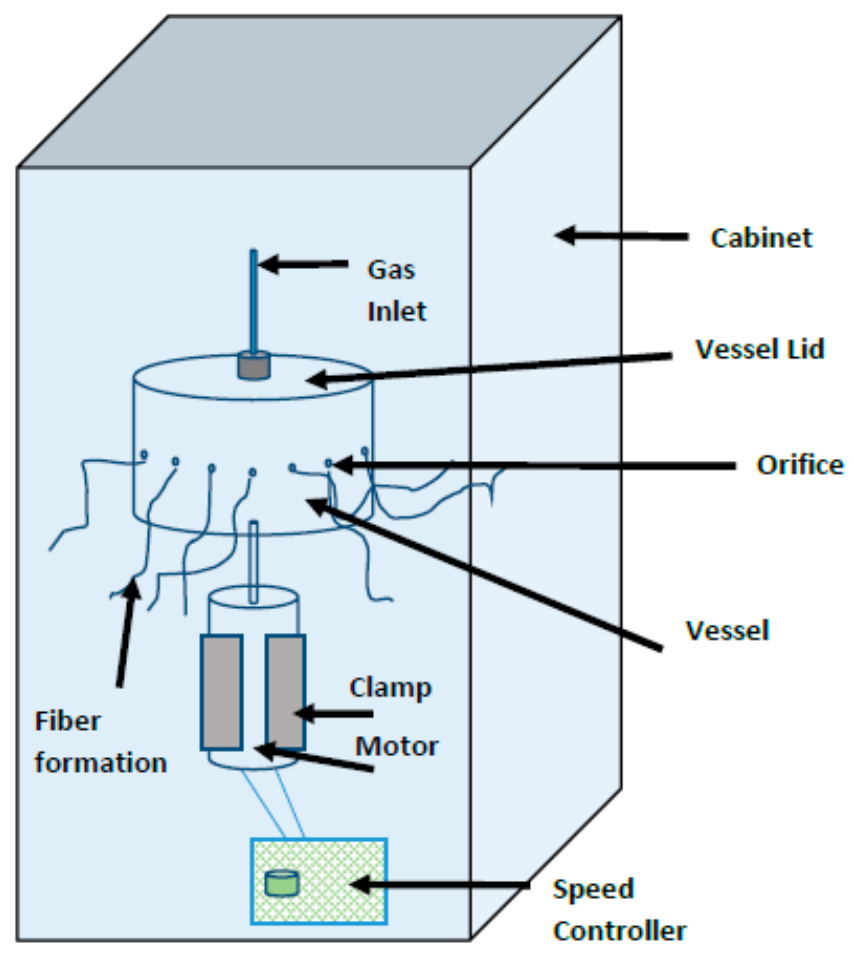

Figure 1. Experimental set-up of the pressurised gyration rig used in this work.

\subsection{Fiber Characterisation}

\section{Scanning Electron Microscopy (SEM)}

The fiber morphology was assessed using SEM (Quanta 200 FEG ESEM, FEI, Hillsborough, OR, USA and JEOL JSM-6301F, Peabody, MA, USA). Prior to imaging, the samples were coated with $20 \mathrm{~nm}$ of gold under argon using a Quorum Q150T Turbo-Pumped Sputter Coater. All SEM images were captured at an acceleration voltage of $5 \mathrm{kV}$. The average fiber diameter and average pore diameter was determined by measuring diameters and pores at over 50 points in the SEM images using the ImageJ software (National Institute of Health, Bethesda, MD, USA).

\section{Results and Discussion}

\section{Evaluation of Microstructure of PMMA Fibers}

The selection of an appropriate solvent or solvent system to prepare polymer solutions based on the solubility parameters between the polymer and solvent/solvent system is a crucial step in any fiber forming process. The solvent with the highest solubility is not always the best solvent for the production of fibers as the solvents physical parameters, such as surface tension, viscosity, vapour pressure and boiling point affect the spinning process [18]. The Flory-Huggins interaction parameterchi $\left(\chi_{12}\right)$ [35] gives a measure of the interaction of the polymer chains with the solvent molecules as well as the polymer-polymer interaction. The $\chi_{12}$ parameter for polymer solutions was calculated from the equation given below [36].

$$
\chi_{12}=\left(\delta_{\mathrm{p}}-\delta_{\mathrm{s}}\right)^{2} \times\left(V_{\mathrm{mol}} / \mathrm{R} T\right)
$$

In here, subscripts s and $\mathrm{p}$ denote solvent and polymer, respectively. $\delta$ and $V_{\mathrm{mol}}$ are the solubility parameter and the molecular volume, respectively, of the solvent at temperature $T(298 \mathrm{~K})$. $\mathrm{R}$ is a universal gas constant. In general, solvents with $\chi_{12}$ between 0 and 0.5 are considered as good solvents and the solvents with $\chi_{12}>0.5$ are considered as poor solvents [37]. The calculated $\chi_{12}$ values 
for each solvent are listed in Table 1. It is found that $\chi_{12}$ for acetone, chloroform, DCM and DMF is $<0.5$, hence these can be classified as good solvents for PMMA. In these solvents, PMMA chains overlap less and there is a greater interaction with the polymer-solvent molecules. The above equation does not account for secondary forces such as polar/non-polar interaction and hydrogen bonding. Therefore, there are exceptions; the calculated $\chi_{12}$ for ethyl acetate is 0.64 , even though ethyl acetate has this high $\chi_{12}$ value it was able to dissolve PMMA due to its high polarity and greater ability to make hydrogen bonds with PMMA chains.

Furthermore, the degree of affinities between polymer and solvent can be expressed by the solubility parameter distance $R_{\mathrm{a}}$. Values of $R_{\mathrm{a}}$ for the solvents used in this study were calculated using Hansen solubility parameters for each solvent using Equation (2) [38] and these are listed in Table 1.

$$
R_{\mathrm{a}}=\left[4\left(\delta \mathrm{d}_{2}-\delta \mathrm{d}_{1}\right)^{2}+\left(\delta \mathrm{p}_{2}-\delta \mathrm{p}_{1}\right)^{2}+\left(\delta \mathrm{h}_{2}-\delta \mathrm{h}_{1}\right)^{2}\right]^{1 / 2}
$$

Here, $\delta \mathrm{d}, \delta \mathrm{p}$, and $\delta \mathrm{h}$ are the solubility parameters representing the dispersion, polar and hydrogen bonding contributions, respectively. Subscripts 1 and 2 represent the solubility parameters for polymer and solvent, respectively. The calculated values $R_{\mathrm{a}}$ show that Acetone $\left(R_{\mathrm{a}}=3.72\right)$ and DMF $\left(R_{\mathrm{a}}=3.99\right)$ show higher affinity to PMMA compare to other solvents. This may be one of the factors that cause non-porous fibers with these solvents.

Table 1. Physical properties of PMMA and solution parameters of solvents used in this study. $\delta$ and $\chi$ values were obtained from reference [36].

\begin{tabular}{ccccccc}
\hline & PMMA & Chloroform & Acetone & DMF & Ethyl Acetate & DCM \\
\hline Molecular Volume $\left(\mathrm{cm}^{3} \cdot \mathrm{mol}^{-1}\right)$ & - & 79.70 & 73.52 & 76.95 & 98.50 & 63.90 \\
Vapour pressure $(\mathrm{mm} / \mathrm{Hg})$ & - & 160 & 184 & 2.70 & 73 & 353 \\
Vapour density (vs. air) & - & 4.1 & 2 & 2.5 & 3 & 2.9 \\
Boiling point $\left({ }^{\circ} \mathrm{C}\right)$ & - & 61 & 56 & 153 & 77 & 40 \\
$\delta \mathrm{D}\left(\mathrm{J} \cdot \mathrm{cm}^{3}\right)^{1 / 2}$ & 17.00 & 17.80 & 15.50 & 17.40 & 15.80 & 18.20 \\
$\delta \mathrm{P}\left(\mathrm{J} \cdot \mathrm{cm}^{3}\right)^{1 / 2}$ & 5.80 & 3.10 & 10.40 & 13.70 & 5.30 & 6.30 \\
$\delta \mathrm{h}\left(\mathrm{J} \cdot \mathrm{cm}^{3}\right)^{1 / 2}$ & 9.20 & 5.70 & 7.00 & 11.30 & 7.20 & 6.10 \\
$\delta\left(\mathrm{J} \cdot \mathrm{cm}^{3}\right)^{1 / 2}$ & 22.20 & 18.95 & 19.93 & 24.86 & 18.20 & 20.20 \\
$\chi_{12}^{1 / 2}$ & - & 0.34 & 0.15 & 0.22 & 0.64 & 0.10 \\
$\mathrm{Ra}$ & - & 8.25 & 3.72 & 3.99 & 5.98 & 5.67 \\
\hline
\end{tabular}

Figures 2-4 show the low- and high-magnification images of the fibers obtained from various solvents. Samples prepared from chloroform, DCM and ethyl acetate exhibit surface pores while samples from acetone and DMF did not show any surface pores. The cross-sectional images of the samples are shown in Figure 5 and indicate that the pores are only a surface feature. In previous literature, the formation of hierarchical structures from different solvents was mainly attributed to the volatility of solvent, phase separation and due to breath figures [1,4]. These researchers paid less attention to the solubility of polymer in each solvent. The formation of breath figures is a very complicated process and there is no common mechanism to explain all experimental results [39]. When highly volatile solvents such as chloroform, ethyl acetate and DCM start to evaporate, the temperature at the air-liquid interface will decrease rapidly due to the enthalpy of vaporization. It was reported that the temperature of a chloroform solution can fall between 0 to $-6{ }^{\circ} \mathrm{C}$ during evaporation [40]. This temperature drop significantly lowers the dew point of the atmosphere; thus, water vapour can condense on the surface of the fiber at random positions. These water droplets then sink in to the fiber core or cause indentations on the surfaces. When water droplets evaporate from the fibers, their imprints remain as pores on the fibers [41,42]. Pores are only on the surface because chloroform, ethyl acetate and DCM are immiscible with water and this limits the penetration of these water droplets to the fiber core. Also, the rate of solvent evaporation on the surface of the polymer jet and the solvent diffusion from the core of the jet to the surface of the polymer jet determines the final structure of the fiber. 


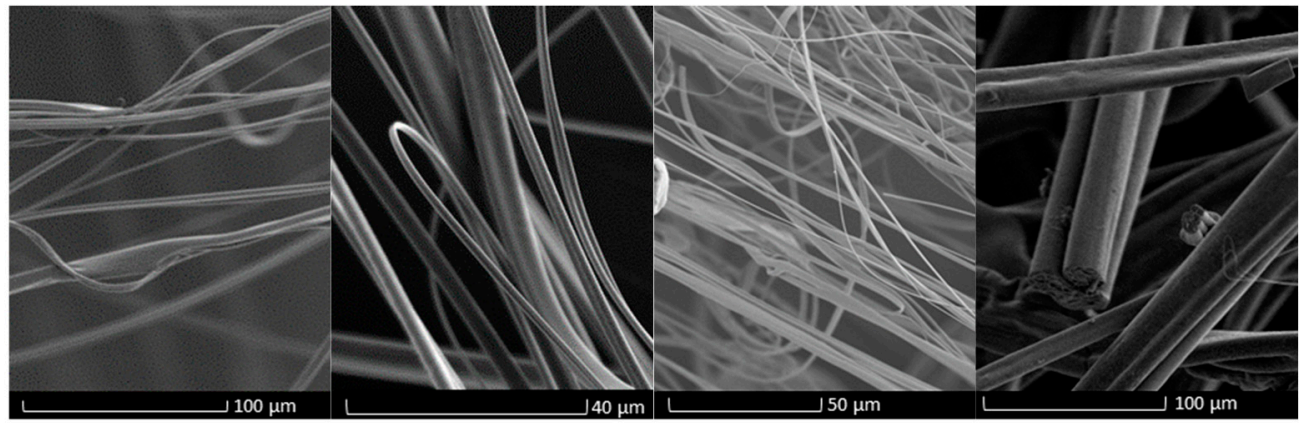

Co

C1

C2

C3
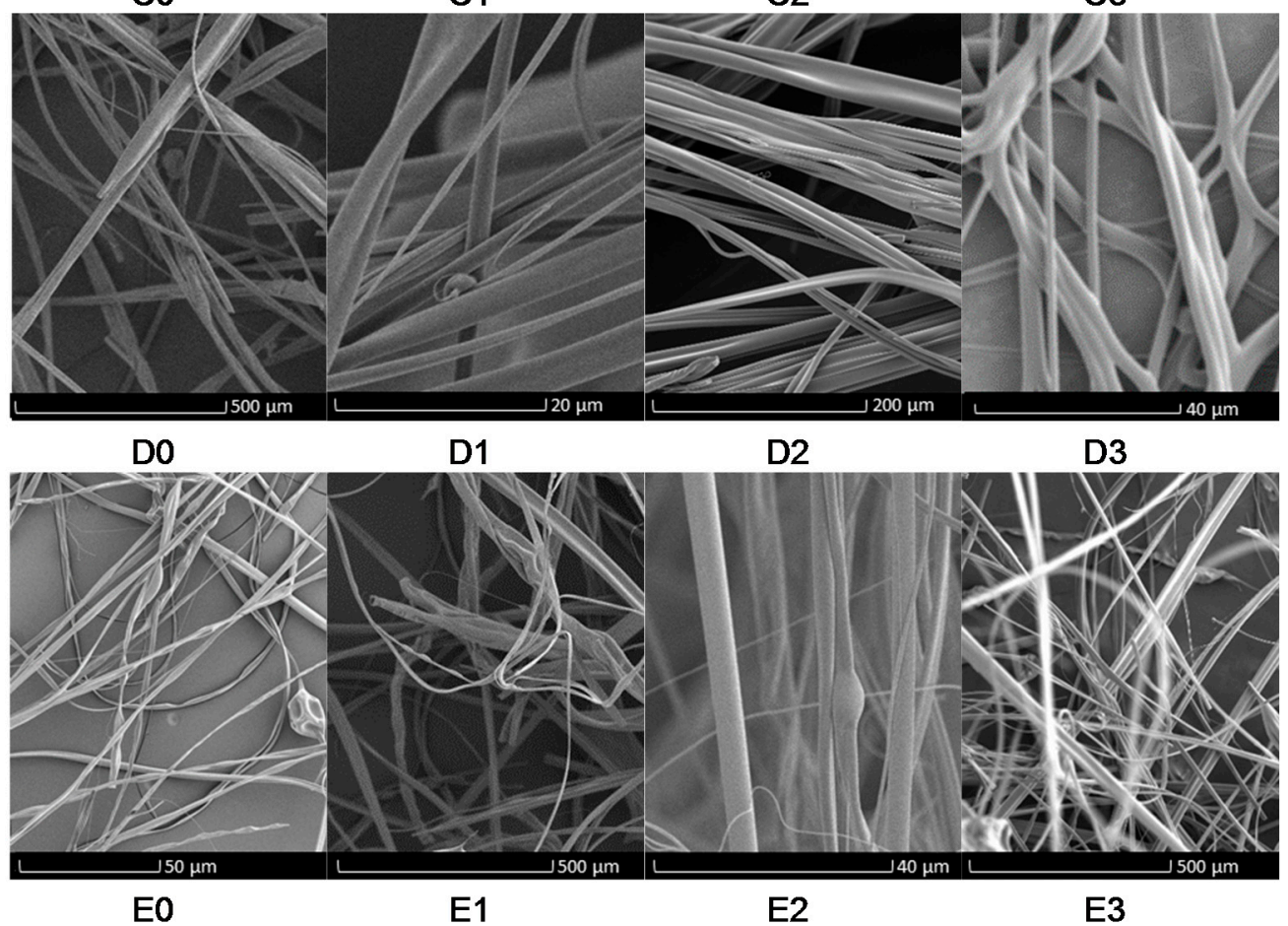

Figure 2. Scanning electron micrographs of poly(methylmethacrylate) (PMMA) fibers prepared using different solvents and different working pressure: (C0-C3) fibers made using chloroform 0, 0.1, 0.2, 0.3 MPa working pressure, respectively; (D0-D3) fibers made using DCM 0, 0.1, 0.2, $0.3 \mathrm{MPa}$ working pressure, respectively; (E0-E3) fibers made using ethyl acetate 0, 0.1, 0.2, 0.3 MPa working pressure, respectively.

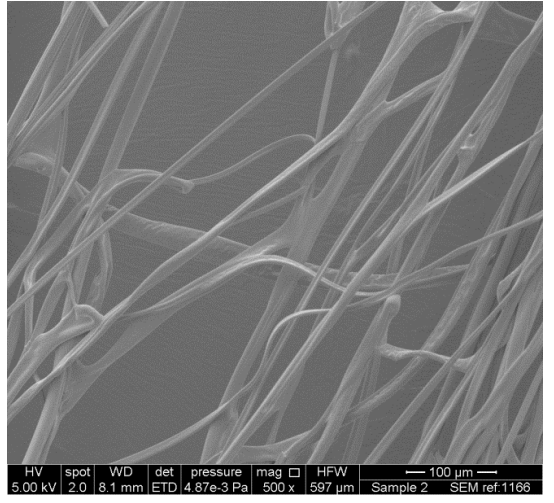

(a)

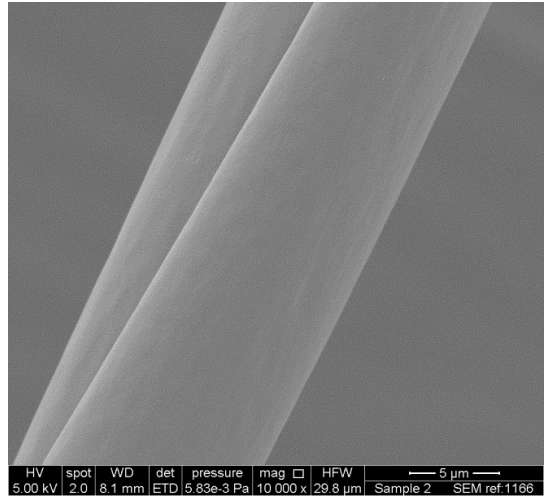

(a1)

Figure 3. Cont. 


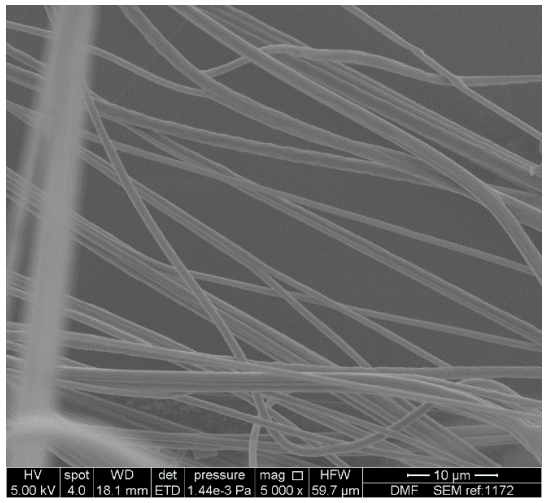

(b)

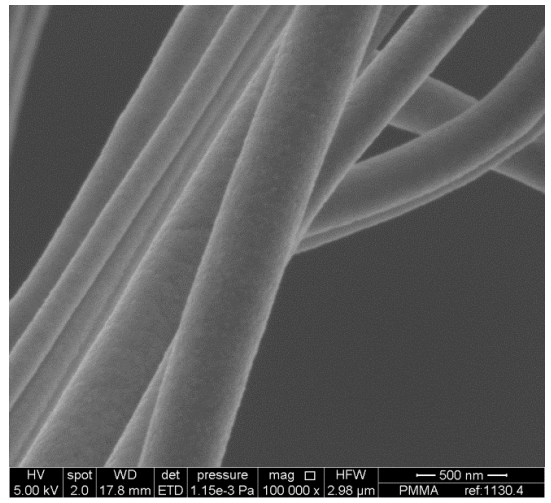

(b1)

Figure 3. Scanning electron micrographs of PMMA fibers prepared using $(\mathbf{a}, \mathbf{a 1})$ acetone as the solvent and (b,b1) N,N-dimethylformamide (DMF) as the solvent.
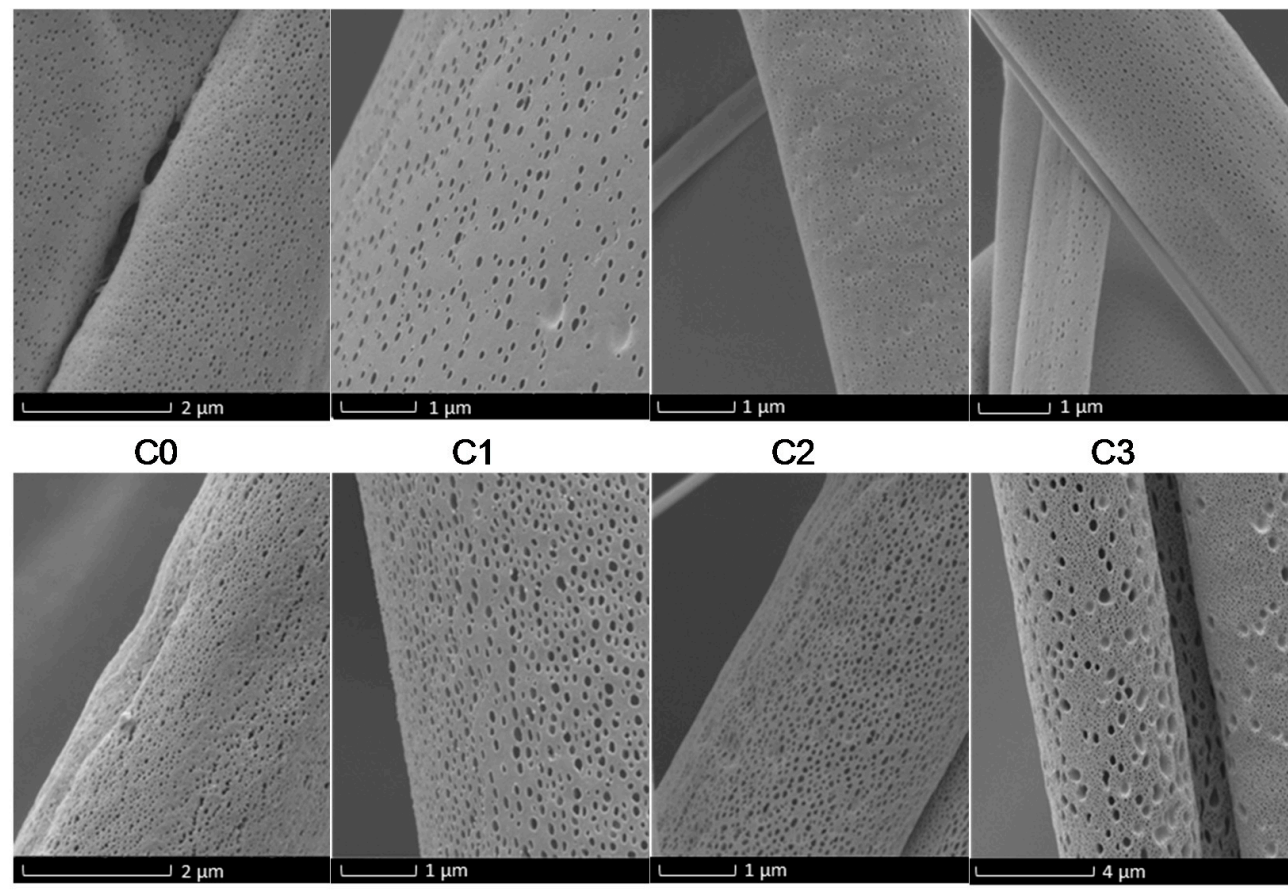

C1

$\mathrm{C} 2$

C3

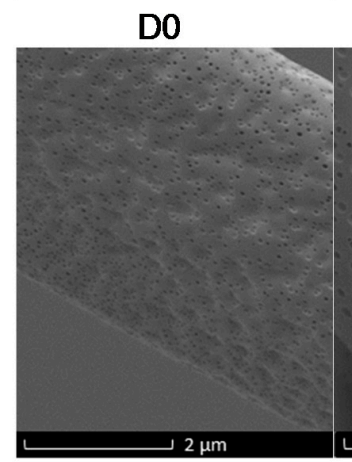

EO

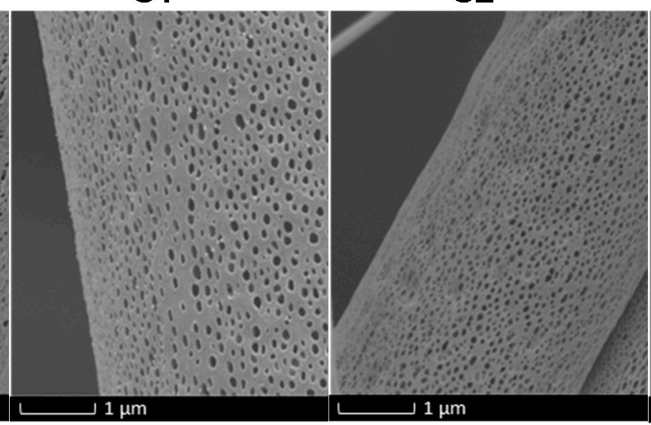

D1

D2

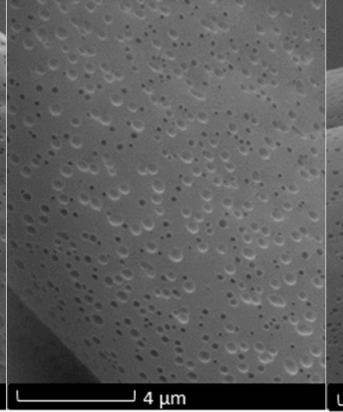

E1

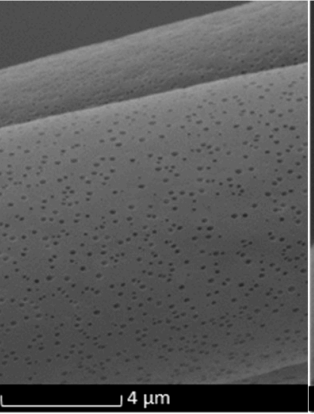

E2

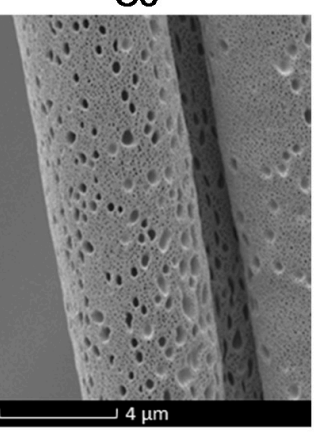

D3

Figure 4. Higher magnification scanning electron micrographs of PMMA fibers prepared using different solvents and different working pressure: $(\mathbf{C} 0-\mathbf{C} 3)$ fibers made using chloroform 0, 0.1, 0.2, 0.3 $\mathrm{MPa}$ working pressure, respectively; (D0-D3) fibers made using DCM 0, 0.1, 0.2, $0.3 \mathrm{MPa}$ working pressure, respectively; (E0-E3) fibers made using ethyl acetate 0, 0.1, 0.2, $0.3 \mathrm{MPa}$ working pressure, respectively. 


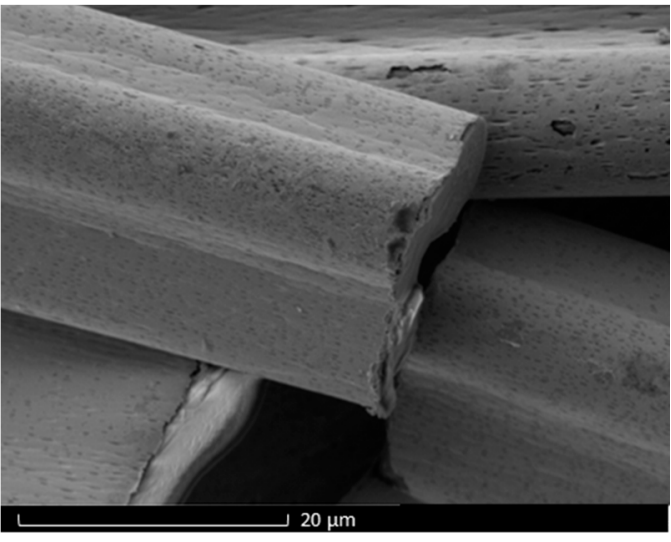

(a)

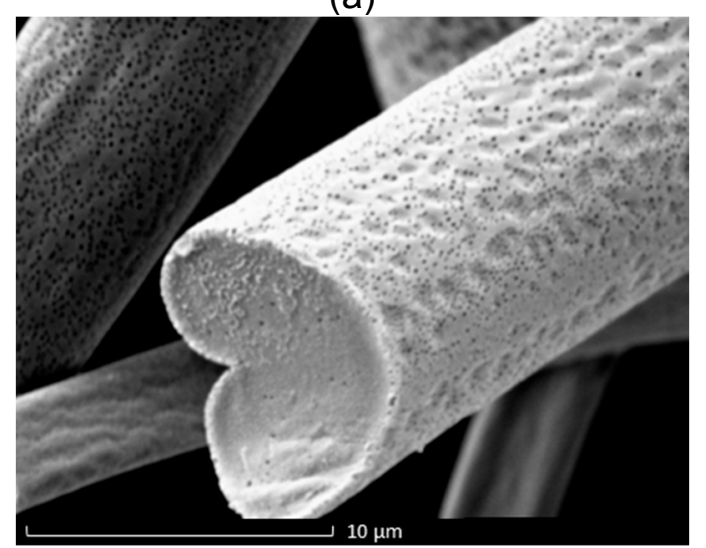

(b)

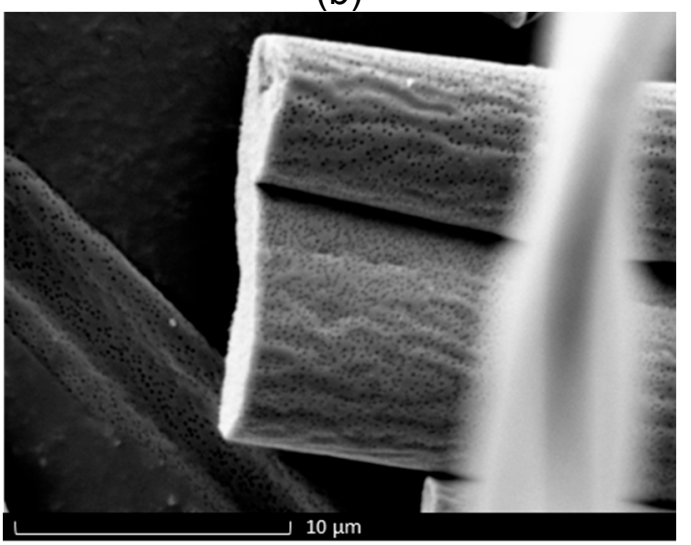

(c)

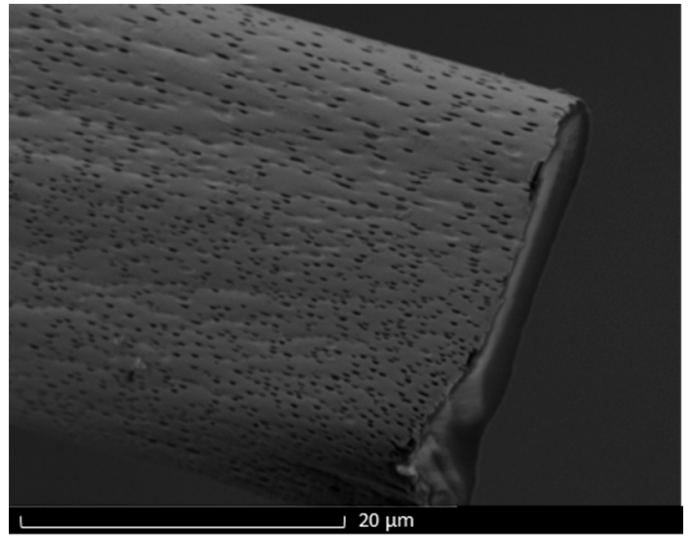

(a1)

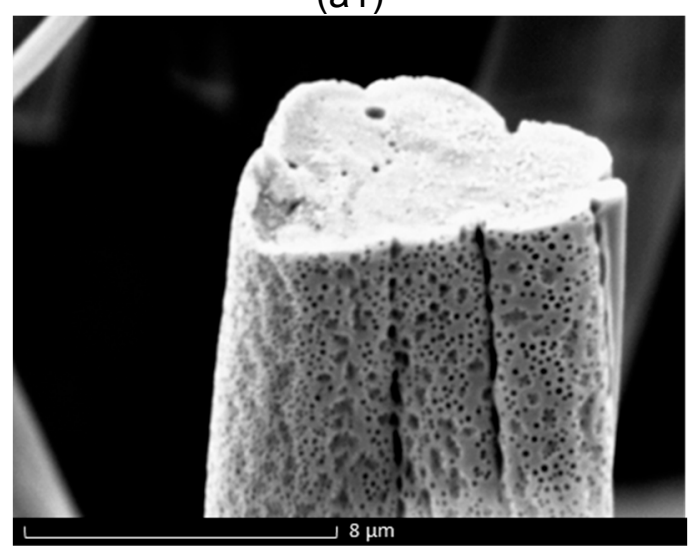

(b1)

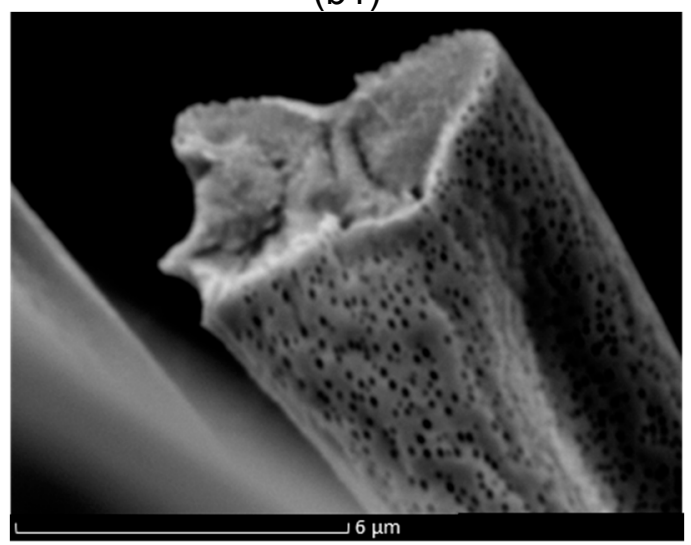

(c1)

Figure 5. Scanning electron microscope images of cross sections of PMMA fibers: chloroform (a,a1); dichloromethane (DCM) (b,b1); ethyl acetate (c,c1).

The measured fiber diameters of the fabricated fibers are listed in Table 2. The fiber diameter data show that the smallest microfibers $(1 \pm 0.4 \mu \mathrm{m})$ were obtained when using DMF as solvent and the largest microfibers $(11 \pm 3 \mu \mathrm{m})$ were obtained when using acetone as solvent. Like our previous work with PEO/water system [5], the fiber diameter did not significantly decrease with increase of applied pressure in the PMMA/solvent systems. This is likely to be caused by the highly volatile solvents used in this study. Therefore, increased air flow caused by increase in applied pressure seems not to appreciably increase polymer jet elongation, resulting in fibers with roughly similar diameters. The PMMA fibers obtained from DMF show smooth surfaces (Figure 3). DMF has less volatility compared to other solvents; therefore, DMF evaporation from the surface is slower than the DMF 
diffusion from the core. This allows the formation of cylindrical fibers. DMF and water vapour are miscible. Therefore, the water vapour formed due to DMF evaporation can diffuse into the polymer jet rather than deposit on the polymer jet, resulting in fibers with a smooth surface. However, it should be noted well that recent work done by Kuroda et al. [43] described the formation of surface pores on a hyperbranched polystyrene film when using tetrahydrofuran as the solvent which is highly miscible with water. If the solvent evaporation on the surface is faster than solvent diffusion from the core, it will result in flat fibers with ribbon-like cross-sections [12]. This was observed when using acetone as the solvent, resulting in fibers with larger diameter. Acetone volatility is relatively similar to chloroform, ethyl acetate and DCM. However, these fibers were not porous (Figure 3). From this observation it can be concluded that formation of porous fibers is not purely based on solvent volatility. When considering acetone-PMMA, DMF-PMMA interaction, $\chi_{12}$ values are 0.15 and 0.22 , respectively, which are relatively similar to chloroform and DCM. This suggests that formation of pores is not purely due to polymer-solvent interaction. The $\delta P$ values for acetone (10.4) and DMF (13.7) are significantly high compared to chloroform (3.1), DCM (6.3) and ethyl acetate (5.3). This may be the reason for obtaining fibers with smooth surfaces.

Table 2. Measured fiber diameter of the fabricated fibers.

\begin{tabular}{cccccc}
\hline \multirow{2}{*}{ Pressure (MPa) } & \multicolumn{5}{c}{ Fiber Diameter $(\mu \mathrm{m})$} \\
\cline { 2 - 6 } & Chloroform & Dichloromethane & Ethyl Acetate & DMF & Acetone \\
\hline 0 & $2.9 \pm 2.5$ & $5.5 \pm 2.2$ & $4.5 \pm 2.3$ & - & - \\
0.1 & $3.3 \pm 1.2$ & $4.3 \pm 2.1$ & $5.1 \pm 1.1$ & $1 \pm 0.4$ & $11 \pm 3$ \\
0.2 & $2.9 \pm 1.5$ & $3.9 \pm 1.6$ & $4.8 \pm 2.3$ & - & - \\
0.3 & $2.8 \pm 1.8$ & $3.7 \pm 1.9$ & $4.7 \pm 2.8$ & - & - \\
\hline
\end{tabular}

It was observed from SEM images (C0, D0, E0) that fibers prepared without applied pressure $(0 \mathrm{MPa})$ have rough/non-uniform surfaces compared to fibers formed with applied pressure. This is possibly due to the different rate of solvent evaporation in the absence of the working pressure. Further, it was observed that when the applied pressure increases from 0.1 to $0.3 \mathrm{MPa}$, the fiber diameter was slightly reduced for all three solvents (Table 2). This is because higher working pressure promotes polymer jet elongation thereby reducing fiber diameter. A similar trend was observed with other polymers such as poly(ethylene oxide) [5] and Nylon [44].

The pore diameters of the fabricated fibers are shown in Table 3. A clear trend between the applied pressure and pore diameter cannot be established from the experimental observations. The formation of surface pores is a complex process as described in pervious literature $[4,41]$. The temperature change on the surface of the polymer jet during solvent evaporation plays a key role in the formation of these nanopores [4]. Therefore, varying the applied pressure during gyration alters the rate of solvent evaporation and, consequently, the temperature of the surface of the fiber jet. However, presented data clearly shows that fibers with desired nanopores (ranging from 40 to $400 \mathrm{~nm}$ ) can be fabricated by carefully selecting the solvent and applied working pressure. Formation of nanopores and their size cannot be effectively controlled during electrospinning by varying processing parameters such as applied voltage, flow rate or collection distance. This is a unique advantage of our process compared to electrospinning and other porous structure-making techniques.

The nanopores on the fibers formed using chloroform were elliptical in shape and their longer dimension is oriented with the fiber axis, while the pores in fibers from DCM and ethyl acetate were more spherical (Figure 4). Formation of porous electrospun PMMA fibers were previously reported when using chloroform, DCM and ethyl acetate as the solvent $[14,16]$. These observations cannot directly compare with gyrospun fibers as the surface of the polymer jet in gyration is charge-free compared to the polymer jet in electrospinning. The electrical charge in the electrospun jet slows down solvent evaporation from the jet and thereby retards phase separation [16]. Furthermore, fibers formed using ethyl acetate showed bead-on string morphology. Such structures are formed 
when the concentration of polymer in solution is either low or high compared to critical spinning concentration [45]. When considering $\chi_{\mathbf{1 2}}$ values, the highest value is obtained for ethyl acetate, which is 0.64, indicating that ethyl acetate interacts less with PMMA, thereby resulting in beaded fibers.

Table 3. Measured pore size of the fabricated fibers.

\begin{tabular}{cccc}
\hline \multirow{2}{*}{ Pressure (MPa) } & \multicolumn{3}{c}{ Pore Size (nm) } \\
\cline { 2 - 4 } & Chloroform & Dichloromethane & Ethyl Acetate \\
\hline 0 & $54 \pm 12$ & $42 \pm 12$ & $121 \pm 23$ \\
0.1 & $126 \pm 18$ & $126 \pm 33$ & $199 \pm 54$ \\
0.2 & $109 \pm 20$ & $104 \pm 43$ & $400 \pm 80$ \\
0.3 & $44 \pm 10$ & $220 \pm 180$ & $124 \pm 23$ \\
\hline
\end{tabular}

\section{Conclusions}

In this study, we examined the formation of different hierarchical structures of PMMA by varying the solvent. It was clearly evident from the interaction and solubility parameters that each solvent behaves differently with respect to PMMA. The swelling of PMMA chains and their chain engagement can be predicted and shows that polymer-solvent interactions vary from solvent to solvent and these interactions play a major role in formation of the hierarchical structures. This study uncovered that by selecting appropriate solvent and applied pressure, it is possible to fabricate microfibers of PMMA with various surface morphologies using pressurised gyration. The creation of microfibers of PMMA with nanopores on the surface is a distinctive outcome.

Acknowledgments: The authors would like to thank David McCarthy (University College London, School of Pharmacy) and Tom Gregory (University College London, Department of Archaeology) for their assistance with scanning electron microscopy. The authors thank the UK Engineering \& Physical Sciences Research Council (EPSRC) for supporting gyratory forming research at University College London, SM is currently supported by EPSRC grant EP/N034228/1.

Author Contributions: U. Eranka Illangakoon and Mohan Edirisinghe conceived and designed the experiments; U. Eranka Illangakoon and Rupy K. Matharu performed the experiments; Suntharavathanan Mahalingam and Rupy K. Matharu analyzed the data; Mohan Edirisinghe contributed reagents/materials/analysis tools; U. Eranka Illangakoon, Suntharavathanan Mahalingam and Mohan Edirisinghe wrote the paper.

Conflicts of Interest: The authors declare no conflict of interest.

\section{References}

1. Megelski, S.; Stephens, J.S.; Chase, D.B.; Rabolt, J.F. Micro- and nanostructured surface morphology on electrospun polymer fibers. Macromolecules 2002, 35, 8456-8466. [CrossRef]

2. Tayi, A.S.; Pashuck, E.T.; Newcomb, C.J.; McClendon, M.T.; Stupp, S.I. Electrospinning bioactive supramolecular polymers from water. Biomacromolecules 2014, 15, 1323-1327. [CrossRef] [PubMed]

3. Pontailler, M.; Illangakoon, E.; Williams, G.R.; Marijon, C.; Bellamy, V.; Balvay, D.; Autret, G.; Vanneaux, V.; Larghero, J.; Planat-Benard, V.; et al. Polymer-based reconstruction of the inferior vena cava in rat: Stem cells or rgd peptide? Tissue Eng. A 2015, 21, 1552-1564. [CrossRef] [PubMed]

4. Yazgan, G.; Dmitriev, R.I.; Tyagi, V.; Jenkins, J.; Rotaru, G.M.; Rottmar, M.; Rossi, R.M.; Toncelli, C.; Papkovsky, D.B.; Maniura-Weber, K.; et al. Steering surface topographies of electrospun fibers: Understanding the mechanisms. Sci. Rep. 2017, 7, 158. [CrossRef] [PubMed]

5. Mahalingam, S.; Edirisinghe, M. Forming of polymer nanofibers by a pressurised gyration process. Macromol. Rapid Commun. 2013, 34, 1134-1139. [CrossRef] [PubMed]

6. Mahalingam, S.; Raimi-Abraham, B.T.; Craig, D.Q.M.; Edirisinghe, M. Solubility-spinnability map and model for the preparation of fibres of polyethylene (terephthalate) using gyration and pressure. Chem. Eng. J. 2015, 280, 344-353. [CrossRef]

7. Illangakoon, U.E.; Mahalingam, S.; Colombo, P.; Edirisinghe, M. Tailoring the surface of polymeric nanofibres generated by pressurised gyration. Surf. Innov. 2016, 4, 167-178. [CrossRef] 
8. Illangakoon, U.E.; Mahalingam, S.; Wang, K.; Cheong, Y.K.; Canales, E.; Ren, G.G.; Cloutman-Green, E.; Edirisinghe, M.; Ciric, L. Gyrospun antimicrobial nanoparticle loaded fibrous polymeric filters. Mater. Sci. Eng. C 2017, 74, 315-324. [CrossRef] [PubMed]

9. Raimi-Abraham, B.T.; Mahalingam, S.; Davies, P.J.; Edirisinghe, M.; Craig, D.Q.M. Development and characterization of amorphous nanofiber drug dispersions prepared using pressurized gyration. Mol. Pharm. 2015, 12, 3851-3861. [CrossRef] [PubMed]

10. Xu, Z.W.; Mahalingam, S.; Basnett, P.; Raimi-Abraham, B.; Roy, I.; Craig, D.; Edirisinghe, M. Making nonwoven fibrous poly(epsilon-caprolactone) constructs for antimicrobial and tissue engineering applications by pressurized melt gyration. Macromol. Mater. Eng. 2016, 301, 922-934. [CrossRef]

11. Mahalingam, S.; Ren, G.G.; Edirisinghe, M.J. Rheology and pressurised gyration of starch and starch-loaded poly(ethylene oxide). Carbohydr. Polym. 2014, 114, 279-287. [CrossRef] [PubMed]

12. Li, L.; Li, R.; Li, M.; Rong, Z.; Fang, T. Theoretical selection of solvent for production of electrospun pmma fibers with wrinkled surfaces. RSC Adv. 2014, 4, 27914-27921. [CrossRef]

13. Feldman, D. Polymer chemistry-The basic concepts, p. C. Hiemenz, Marcel Dekker, New York, 1984, 738 pp. No price given. J. Polym. Sci. Polym. Lett. Ed. 1984, 22, 673. [CrossRef]

14. Li, L.; Jiang, Z.; Li, M.; Li, R.; Fang, T. Hierarchically structured pmma fibers fabricated by electrospinning. RSC Adv. 2014, 4, 52973-52985. [CrossRef]

15. Dayal, P.; Liu, J.; Kumar, S.; Kyu, T. Experimental and theoretical investigations of porous structure formation in electrospun fibers. Macromolecules 2007, 40, 7689-7694. [CrossRef]

16. Liu, J.; Bauer, A.J.P.; Li, B. Solvent vapor annealing: An efficient approach for inscribing secondary nanostructures onto electrospun fibers. Macromol. Rapid Commun. 2014, 35, 1503-1508. [CrossRef] [PubMed]

17. Selling, G.W.; Biswas, A.; Patel, A.; Walls, D.J.; Dunlap, C.; Wei, Y. Impact of solvent on electrospinning of zein and analysis of resulting fibers. Macromol. Chem. Phys. 2007, 208, 1002-1010. [CrossRef]

18. Pattamaprom, C.; Hongrojjanawiwat, W.; Koombhongse, P.; Supaphol, P.; Jarusuwannapoo, T.; Rangkupan, R. The influence of solvent properties and functionality on the electrospinnability of polystyrene nanofibers. Macromol. Mater. Eng. 2006, 291, 840-847. [CrossRef]

19. Haas, D.; Heinrich, S.; Greil, P. Solvent control of cellulose acetate nanofibre felt structure produced by electrospinning. J. Mater. Sci. 2010, 45, 1299-1306. [CrossRef]

20. Zheng, J.; Zhang, H.; Zhao, Z.; Han, C.C. Construction of hierarchical structures by electrospinning or electrospraying. Polymer 2012, 53, 546-554. [CrossRef]

21. Celebioglu, A.; Uyar, T. Electrospun porous cellulose acetate fibers from volatile solvent mixture. Mater. Lett. 2011, 65, 2291-2294. [CrossRef]

22. Ye, X.-Y.; Lin, F.-W.; Huang, X.-J.; Liang, H.-Q.; Xu, Z.-K. Polymer fibers with hierarchically porous structure: Combination of high temperature electrospinning and thermally induced phase separation. RSC Adv. 2013, 3, 13851-13858. [CrossRef]

23. Sainudeen, S.S.; Asok, L.B.; Varghese, A.; Nair, A.S.; Krishnan, G. Surfactant-driven direct synthesis of a hierarchical hollow mgo nanofiber-nanoparticle composite by electrospinning. RSC Adv. 2017, 7, 35160-35168. [CrossRef]

24. Tang, S.; Tian, B.; Ke, Q.-F.; Zhu, Z.-A.; Guo, Y.-P. Gentamicin-loaded carbonated hydroxyapatite coatings with hierarchically porous structures: Drug delivery properties, bactericidal properties and biocompatibility. RSC Adv. 2014, 4, 41500-41509. [CrossRef]

25. Bai, H.; Walsh, F.; Gludovatz, B.; Delattre, B.; Huang, C.; Chen, Y.; Tomsia, A.P.; Ritchie, R.O. Bioinspired hydroxyapatite/poly(methyl methacrylate) composite with a nacre-mimetic architecture by a bidirectional freezing method. Adv. Mater. 2016, 28, 50-56. [CrossRef] [PubMed]

26. Jacobs, E.; Saralidze, K.; Roth, A.K.; de Jong, J.J.A.; van den Bergh, J.P.W.; Lataster, A.; Brans, B.T.; Knetsch, M.L.W.; Djordjevic, I.; Willems, P.C.; et al. Synthesis and characterization of a new vertebroplasty cement based on gold-containing pmma microspheres. Biomaterials 2016, 82, 60-70. [CrossRef] [PubMed]

27. Caro-Osorio, E.; De la Garza-Ramos, R.; Martínez-Sánchez, S.R.; Olazarán-Salinas, F. Cranioplasty with polymethylmethacrylate prostheses fabricated by hand using original bone flaps: Technical note and surgical outcomes. Surg. Neur. Int. 2013, 4, 136. [CrossRef] [PubMed]

28. Canché-Escamilla, G.; Duarte-Aranda, S.; Toledano, M. Synthesis and characterization of hybrid silica/pmma nanoparticles and their use as filler in dental composites. Mater. Sci. Eng. C 2014, 42, 161-167. [CrossRef] [PubMed] 
29. Langer, R.; Tirrell, D.A. Designing materials for biology and medicine. Nature 2004, 428, 487-492. [CrossRef] [PubMed]

30. Peppas, N.A.; Langer, R. New challenges in biomaterials. Science 1994, 263, 1715-1720. [CrossRef] [PubMed]

31. Zupančič, Š.; Sinha-Ray, S.; Sinha-Ray, S.; Kristl, J.; Yarin, A.L. Long-term sustained ciprofloxacin release from pmma and hydrophilic polymer blended nanofibers. Mol. Pharm. 2016, 13, 295-305. [CrossRef] [PubMed]

32. Brint, S.F.; Ostrick, D.M.; Bryan, J.E. Keratometric cylinder and visual performance following phacoemulsification and implantation with silicone small-incision or poly(methyl methacrylate) intraocular lenses. J. Cataract. Refract. Surg. 1991, 17, 32-36. [CrossRef]

33. Morariu, M.D.; Voicu, N.E.; Schaffer, E.; Lin, Z.; Russell, T.P.; Steiner, U. Hierarchical structure formation and pattern replication induced by an electric field. Nat Mater 2003, 2, 48-52. [CrossRef] [PubMed]

34. Deng, R.; Liu, S.; Liang, F.; Wang, K.; Zhu, J.; Yang, Z. Polymeric janus particles with hierarchical structures. Macromolecules 2014, 47, 3701-3707. [CrossRef]

35. Hansen, C.M. Hansen Solubility Parameters: A user's Handbook; CRC Press: Boca Raton, FL, USA, 2007.

36. Pang, H.; Bao, Y.; Xu, L.; Yan, D.-X.; Zhang, W.-Q.; Wang, J.-H.; Li, Z.-M. Double-segregated carbon nanotube-polymer conductive composites as candidates for liquid sensing materials. J. Mater. Chem. A 2013, 1, 4177-4181. [CrossRef]

37. Feller, J.F.; Lu, J.; Zhang, K.; Kumar, B.; Castro, M.; Gatt, N.; Choi, H.J. Novel architecture of carbon nanotube decorated poly(methyl methacrylate) microbead vapour sensors assembled by spray layer by layer. J. Mater. Chem. 2011, 21, 4142-4149. [CrossRef]

38. Liu, Z.; Zhao, J.-H.; Liu, P.; He, J.-H. Tunable surface morphology of electrospun pmma fiber using binary solvent. Appl. Surf. Sci. 2016, 364, 516-521. [CrossRef]

39. Zhang, A.; Bai, H.; Li, L. Breath figure: A nature-inspired preparation method for ordered porous films. Chem. Rev. 2015, 115, 9801-9868. [CrossRef] [PubMed]

40. Chiu, Y.-C.; Kuo, C.-C.; Lin, C.-J.; Chen, W.-C. Highly ordered luminescent microporous films prepared from crystalline conjugated rod-coil diblock copolymers of pf-b-psa and their superhydrophobic characteristics. Soft Matter 2011, 7, 9350-9358. [CrossRef]

41. Srinivasarao, M.; Collings, D.; Philips, A.; Patel, S. Three-dimensionally ordered array of air bubbles in a polymer film. Science 2001, 292, 79-83. [CrossRef] [PubMed]

42. Park, M.S.; Kim, J.K. Breath figure patterns prepared by spin coating in a dry environment. Langmuir 2004, 20, 5347-5352. [CrossRef] [PubMed]

43. Kuroda, Y.; Muto, I.; Shimojima, A.; Wada, H.; Kuroda, K. Nanospace-mediated self-organization of nanoparticles in flexible porous polymer templates. Langmuir 2017, 33, 9137-9143. [CrossRef] [PubMed]

44. Xu, Z.; Mahalingam, S.; Rohn, J.L.; Ren, G.; Edirisinghe, M. Physio-chemical and antibacterial characteristics of pressure spun nylon nanofibres embedded with functional silver nanoparticles. Mater. Sci. Eng. C 2015, 56, 195-204. [CrossRef] [PubMed]

45. Hong, X.; Edirisinghe, M.; Mahalingam, S. Beads, beaded-fibres and fibres: Tailoring the morphology of poly(caprolactone) using pressurised gyration. Mater. Sci. Eng. C 2016, 69, 1373-1382. [CrossRef] [PubMed]

(c) 2017 by the authors. Licensee MDPI, Basel, Switzerland. This article is an open access article distributed under the terms and conditions of the Creative Commons Attribution (CC BY) license (http:/ / creativecommons.org/licenses/by/4.0/). 